\title{
COMPLEJIDAD DEL CONOCIMIENTO EN EDUCACIÓN: LA REFORMA EDUCATIVA DEL SIGLO XXI
}

Juan Martín López Calva*

RESUMEN: Con base en la perspectiva del pensamiento complejo de Edgar Morin y la visión humanista integral de Bernard Lonergan, se plantea un paso fundamental para una reforma educativa, en la construcción del conocimiento en la Educación: de la visión simplificadora a la visión compleja. Este paso conducirá a una perspectiva integradora del proceso de construcción de conocimiento en el aula, para llegar a una visión de proceso de enseñanza-aprendizaje.

$$
\text { শ্য }
$$

ABSTRACT: Based on Edgar Morin's complex thinking theory and Bernard Lonegran's holistic humanistic vision, we propose an important step in educational reform in the construction of knowledge in Education, namely a change from a simple vision to a more complex one. This step will permit a more integrating perspective of the construction of knowledge process in the classroom leading to a teaching-learning process.

PALABRAS CLAVE: Conocimiento, complejidad, objetividad, transformación, humanismo. KEY WORDS: Knowledge, complexity, objectivity, transformation, humanism.

RECEPCIÓN: 03 de noviembre de 2011.

APROBACIÓN: 20 de marzo de 2012.

*Universidad Iberoamericana, Puebla. 


\section{COMPLEJIDAD DEL CONOCIMIENTO EN EDUCACIÓN: LA REFORMA EDUCATIVA DEL SIGLO XXI}

Tenemos pues, tres problemas fundamentales respecto a la educación contemporánea: Primero, está el problema de las masas, la manera de educar a todos. Segundo, está el nuevo aprendizaje, que no es meramente un añadido a los antiguos temas, sino su transformación -y funciona de manera diferente en los distintos campos. Finalmente, está el problema de la especialización: el nuevo conocimiento es gigantesco, está dividido y no se ha asimilado.

Lonergan, 1988

Lo que enseña a aprender, eso es el método. No aporto el método, parto a la búsqueda del método.

Morin, 1981

\section{Complejidad: hacia la transformación de la visión del conocimiento en Educación}

$\mathrm{E}_{1}$ problema de la visión del conocimiento que está detrás y se genera por medio de la educación consiste, fundamentalmente, en que esta visión se ha construido desde la racionalidad simplificadora que domina nuestro mundo científico y cultural. Así, el problema de las masas -la necesidad de educar con buena calidad a una enorme cantidad de seres humanos-, el problema de la especialización -el nuevo conocimiento que "es gigantesco, está dividido y no se ha asimilado" y el problema del nuevo aprendizaje que no consiste en hacer un "añadido a los antiguos temas", sino en "su

${ }^{1}$ B. Lonergan, Filosofía de la Educación, 1998, México, ed. Universidad Iberoamericana, p. 45. 
transformación"-, ${ }^{2}$ siguen siendo problemas vigentes hoy día, a más de cincuenta años de su planteamiento por Lonergan, ${ }^{3}$ debido a que no se ha podido superar esta visión simplificadora y reductora del conocimiento y no se ha logrado generar un nuevo fundamento de la educación que pueda revertir este proceso.

El problema principal de la simplificación del conocimiento, para Lonergan, ${ }^{4}$ es la persistencia de las distintas corrientes filosóficas y de nuestra visión del sentido común en considerar el conocimiento como una actividad y no como un proceso complejo, y plantear además que esta actividad simple es equiparable a la visión, es decir, que conocer es como ver lo que está ahí, afuera, ahora. De alguna manera, Morin coincide con la afirmación, dado que es muy insistente en señalar que no es posible sostener que el ser humano puede conocer haciendo un retrato fiel y exacto del exterior, sino que todo conocimiento es una traducción de la realidad externa. ${ }^{5}$

De este problema esencial de concepción del conocimiento se desprende una visión errónea de objetividad, que consiste en ver correctamente, lo que está ahí, afuera, ahora, dejando de lado o despojándose de la propia subjetividad que distorsiona ese mirar correctamente, lo cual quiere decir, llevado al extremo, que conocer consiste en mirar, y conocer objetivamente es mirar correctamente, sin la interferencia del sujeto que mira. A partir de esta visión distorsionada de la objetividad se entra en una dinámica que trata de establecer, del modo más estricto y riguroso posible, las reglas del conocimiento objetivo. Estas reglas, básicamente, son de carácter lógico y metodológico. Nos encontramos como resultado con una visión de conocimiento que es rígida y excluyente, y que se centra en el método científico entendido como el único método válido -reglas metodológicas para conocer-y en la lógica clásica -que es disyuntiva y simplificadora por su propia naturaleza-, es decir, en reglas inflexibles de pensamiento y en reglas inflexibles

${ }^{2}$ Ibid., p. 45.

${ }^{3}$ Este libro, traducido al español como "Filosofía de la Educación" es la compilación de una serie de conferencias impartidas por Lonergan en Cincinatti, en 1956.

${ }^{4}$ B. Lonergan, Insight. Estudio sobre la comprensión humana, 1999, Salamanca, ed. Sígueme, Universidad Iberoamericana.

${ }^{5}$ E. Morin, El Método III. El conocimiento del conocimiento, 1999, Madrid, Ediciones Cátedra. 
de procedimiento. Las reglas metodológicas expresadas en el llamado método científico, excluyen o menosprecian cualquier otro método de investigación que se aleje de sus postulados inflexibles. Las reglas lógicas expresadas en los principios de la lógica formal, excluyen o menosprecian cualquier posibilidad de otros modos de pensamiento, que pueden ser a-lógicos o responder a lógicas distintas.

Este esfuerzo por definir y seguir las reglas del conocimiento objetivo nos ha conducido a considerar como conocimiento exclusivamente al conocimiento teórico-científico -sustentado en la visión del método científico único-, y a rechazar y combatir toda forma de pensamiento alternativo, desde el pensamiento del sentido común, que se ve como inferior, hasta el pensamiento mítico que se considera signo de atraso cultural y de superstición.

En el campo educativo, este proceso distorsionado del conocimiento se expresa en currículos dispersos, que están construidos sobre la base de la hiperespecialización y la total separación de las disciplinas, cuya meta de calidad es la acumulación de contenidos bajo el principio de que el sujeto más educado es el que sabe más cosas.

Esta perspectiva del conocimiento como acumulación de ideas o conceptos objetivos se traduce en una concepción de la actividad docente como transmisora de contenidos y en una enseñanza conceptualista y memorista, que busca el almacenamiento de información considerada como verdadera porque viene en los libros de texto. En el mejor de los casos, los procesos de enseñanza-aprendizaje tratan de buscar la comprensión, por parte de los estudiantes, de los conceptos centrales del curso, pero no llegan a la promoción de una auténtica reflexión crítica sobre ellos. En general, la escuela y la universidad enseñan a pensar en objetos simples y no en procesos complejos y lo hacen de una manera que se concentra en los aspectos formales del análisis de esas cosas - conceptualización, formulación adecuada-, pero no en la realidad de las cosas y en la relación de esa realidad con otras realidades contextuales.

De esta manera, el conocimiento desarraigado del sujeto humano que lo produce y del sujeto humanidad para el que se produce, se llama, en educación, conocimiento teórico, lo cual produce un rechazo de edu- 
candos y educadores a la teoría. A este rechazo no se responde mediante un profundo replanteamiento de la visión de conocimiento y una reestructuración curricular que devuelva la vida al conocimiento teórico verdadero, que lo articule y dimensione respecto al conocimiento tradicional o del sentido común y que arraigue nuevamente al ser humano en él, sino con un proceso de degradación pragmatista del conocimiento, que va convirtiendo los contenidos de la educación en simples ideas o recetas prácticas, fácilmente asimilables, que no requieren de pensamiento crítico y que tienen una evidente aplicación utilitaria. Este proceso, como ya hemos dicho, se refuerza en el contexto de una sociedad consumista y utilitarista que premia este tipo de educación porque resulta funcional al sistema.

La carencia de reflexión crítica y la visión conceptualista de la educación embonan perfectamente con una visión positivista de lo educativo, que promueve esta monometodología sustentada en que el conocimiento válido es el que se verifica empíricamente -mira y revisa la mirada correcta- y que no existe otra manera de conocer. En el mejor de los casos, esta visión lleva a una educación en la que los estudiantes verifican empíricamente en el laboratorio lo que dicen los libros y en ocasiones logran comprender el fenómeno estudiado; en la mayoría de las ocasiones, se aprenden los principios científicos y las leyes que explican los fenómenos naturales, simplemente como dogmas incuestionables.

La escuela, entonces, enseña conceptos que en el caso de las ciencias naturales son dogmas de fe, porque se han verificado empíricamente, y en el caso de las ciencias humanas y sociales son simples puntos de vista, o discursos más o menos coherentes y atractivos. Pero la verdad está totalmente ausente de los procesos educativos, porque a ella se llega mediante la reflexión crítica y la afirmación de juicios virtualmente incondicionados; estos procesos no son nada frecuentes en nuestras aulas.

El gran paso necesario respecto al conocimiento en la educación, para aproximarnos a la reforma educativa urgente en el siglo XXI, es el paso de la visión simple a la visión de complejidad. Este primer 
gran paso comprende varios componentes que es necesario tener claros para poder construir una estrategia integral que ayude a lograr esta profunda reforma del conocimiento que genera/es generado por la educación contemporánea.

El paso de la visión simple a la compleja requiere en primer lugar de una transición que nos lleve a considerar al conocimiento no como una actividad simple, similar al ver, sino como un proceso complejo, al que Lonergan entiende como un "esquema normativo de operaciones recurrentes y relacionadas entre sí que producen resultados acumulativos y progresivos" comprende desde la computación unicelular, la computación animal de la estructura humana, la computación cerebral y el proceso de cogitación único en el cerebro humano, que es bihemisférico y triúnico. ${ }^{7}$

El proceso de conocimiento en la educación se enriquecería enormemente, y apuntaría hacia la construcción de procesos de aprendizaje realmente relevantes y significativos, si incorporara la visión bihemisférica del cerebro humano como gran solucionador de problemas (GPS) y tratara explícitamente de desarrollar los procesos intelectuales propios de ambos hemisferios con igual interés e intensidad. El desarrollo del pensamiento analógico, intuitivo y creativo propio del hemisferio derecho, se encuentra en enorme desventaja dentro de un sistema educativo racionalista que ha privilegiado siempre los procesos de pensamiento lógico, racional, lineal y ha llegado a considerar que la única inteligencia es la "inteligencia lógico-matemática". ${ }^{8}$ Un gran avance sería la introducción enfática y sistemática de una nueva visión del conocimiento que articule el potencial de ambos hemisferios. Esto no consiste en la introducción complementaria de cursos de creatividad o de talleres de expresión artística en el currículo, sino en el replanteamiento global del mismo para introducir otra forma de concebir el conocimiento y de trabajarlo en el aula, para que en todas y cada una de las asignaturas se construyan procesos de aprendizaje que potencien de manera inseparable ambos tipos de pensamiento.

${ }^{6}$ B. Lonergan, Método en Teología, 1988, Salamanca, ed. Sígueme, p. 12.

${ }^{7}$ E. Morin, El Método III, op. cit.

${ }^{8}$ H. Gardner, Frames of mind, 1993a, New York, Basic books, Harper Collins ed.; Multiple intelligences: the theory in practice, 1993b, New York,Basic books, Harper Collins ed. 
La introducción simultánea de la visión del cerebro como entidad triúnica en la que la razón, la emoción y la pulsión están interactuando de manera concurrente, complementaria y en ocasiones antagonista en el educando y el educador, sería otro requisito para cambiar la perspectiva del conocimiento en la educación y empezar a hablar de un conocimiento verdaderamente humano. El conocimiento se construye con razón, pero también con pasión y emoción, también incluso con una dosis de pulsión irracional. Incorporar la dimensión emocional y la dimensión pulsional-animal del ser humano al conocimiento, sería reencarnar el conocimiento y darle nuevamente forma humana, contenido humano. Esto haría que se pudiera superar esa falsa visión de lo teórico como algo que no es atractivo para el educando, y que además no tiene relación con su vida ni con la vida de la comunidad. Un proceso de aprendizaje que involucra la pasión, la emoción, la pulsión y la razón del educando sería, sin duda, un proceso de aprendizaje significativo, donde el conocimiento movería todo el mundo del estudiante y ampliaría su horizonte humano.

Un cambio de perspectiva en relación al conocimiento sería tomar en cuenta, además, el análisis del pensamiento mítico en la vida de nuestras sociedades humanas, y que articulara de manera armónica, aunque señalando su tensión, este tipo de pensamiento con el pensamiento científico-racional (mythos-logos); sería un conocimiento mucho más vivo, que hablaría más en profundidad al educando y que llegaría hasta esa parte del inconsciente colectivo que todos compartimos como especie humana, haciéndolo sentir más plenamente cohesionado con su propia naturaleza.

El análisis del mundo de las ideas como un mundo que tiene vida propia y que se rige por sus propias dinámicas, ${ }^{9}$ considerando el modo en que muchas veces los seres humanos "somos poseídos por las ideas que poseemos", sería un elemento fundamental para desterrar la visión dogmática que hace que se sigan corrientes teóricas, hasta convertirlas, por su cerrazón, en verdaderas ideologías inmovilizadoras. Este análisis sería un elemento revitalizante de toda la dinámica de la edu-

${ }^{9}$ E. Morin, El Método IV. Las ideas. Su habitat, su vida, sus costumbres, su organización, 2001, Madrid, Ediciones Cátedra. 
cación en sus distintos niveles y ayudaría a generar conciencia respecto a la necesidad de contar con teorías y propuestas científicas abiertas a la crítica y a la constante autocorrección.

La visión del método trascendental descrito por Lonergan, ${ }^{10}$ aportaría una perspectiva heurística que ayudaría a formar esta visión compleja del conocimiento que no es una actividad, sino todo un conjunto de actividades de distinta naturaleza -empírica, intelectual, reflexivaracional-, que producen resultados que van conformando acumulativamente una herencia, pero que además son progresivos en su claridad, profundidad, pertinencia y veracidad.

La perspectiva de que la experiencia empírica es muy importante en el proceso cognitivo; pero que experimentar no es conocer; que la generación de comprensión inteligente es básica en todo proceso de conocimiento, pero que hacerse una idea de algo no es conocer; y la clara afirmación de que la reflexión crítica y la generación de juicios, de hecho es una fase indispensable para cerrar el proceso de conocimiento, pero que no es conocimiento por sí sola, dado que requiere de experiencia empírica y comprensión inteligente para realizarse, representa sin duda una verdadera revolución copernicana en el proceso de enseñanza-aprendizaje, que solamente cuando se ha llegado a vivir en la experiencia propia, es posible valorar en toda su trascendencia.

En este cambio de perspectiva -'verdadera conversión intelectual', la llama Lonergan - respecto del conocimiento es fundamental la comprensión acerca de la necesidad de distinguir y realizar el paso del segundo al tercer nivel de conciencia. La transición definitiva en nuestra visión sobre lo que es conocer depende de esta transición, que nos lleve a superar la concepción de que el conocimiento es un proceso que termina con la generación de ideas claras y distintas sobre las cosas que están ahí, afuera, ahora y a asumir plenamente, desde nuestra propia experiencia de autoafirmación como sujetos cognoscentes, que el conocimiento es un proceso que solamente culmina con la "aprehensión de lo virtualmente incondicionado", que se expresa en un juicio de hecho probablemente verdadero o verdadero con plena certeza.

${ }^{10}$ B. Lonergan, Método en Teología, 1988,Salamanca, ed. Sígueme. 
Esta transición fundamental incluye la comprensión plena de que un juicio no es una oración o una expresión, es decir, que un juicio no es la expresión de una afirmación o negación sobre la verdad de algo, sino el contenido de esta expresión, que es un incondicionado virtual, ${ }^{11}$ es decir, un condicionado cuya totalidad de condiciones se ha cumplido. Se puede expresar de la misma forma una idea afirmativa y un juicio de hecho, pero el juicio es la respuesta a una pregunta en orden a reflexionar y la idea no lo es. El juicio es, además, el contenido de un acto de juzgar, y la idea no lo es, pues es el contenido de un acto de comprender. De esta manera, no estamos hablando de juicios en el sentido de ideas, que son la conclusión de un silogismo lógico, sino de juicios en el sentido de contenidos de un acto de intelección reflexiva.

Cuando se ha comprendido esto y se logra dar el paso plenamente, se puede trascender el relativismo que se sustenta en que existe una multiplicidad de discursos inteligentes, porque hay una multiplicidad de percepciones de la realidad, pero que concluye erróneamente que por ello existe una multiplicidad de verdades o que no existe ninguna verdad. Se puede también trascender la visión equivocada de objetividad, que excluye al sujeto de su propio conocimiento, y llegar a la convicción que afirma la absolutidad relativa del conocimiento, porque un juicio es absoluto respecto a los datos y la inteligencia y la reflexión crítica que le dieron origen. Porque un juicio es relativamente absoluto, pues es una afirmación virtualmente incondicionada $-\mathrm{y}$ por lo tanto sujeta a condiciones que pueden cumplirse en determinado contexto-.

Esta transición se reflejará indudablemente en el aula, donde se trascenderá el conceptualismo y se buscarán procesos en los que el educando aprenda mediante la experiencia que le aporte datos suficientes y relevantes sobre un fenómeno; que sea capaz de formular preguntas adecuadas, de generar o recibir del docente imágenes pertinentes; que llegue a comprender y a conceptualizar, para generar formulaciones inteligentes del problema; que pueda hacer preguntas para la reflexión crítica; que sea capaz de reunir pruebas, de ponderar la evidencia, de abrirse a la intelección refleja y de llegar a un juicio, cuando ya no existan más preguntas relevantes que hacerle al problema en cuestión.

${ }^{11}$ B. Lonergan, Insight, op. cit., cap. 11. 
De esta manera, se podrá llegar a afirmar juicios verdaderos que expresen la realidad de las cosas que se estudian, sabiendo lo relativamente absolutos que son estos juicios, conociendo las condiciones a las que están ligados y la manera en que se cumplen estas condiciones. Los educadores y los educandos podrán ser conscientes de la vulnerabilidad o invulnerabilidad de las afirmaciones que se hacen en el aula, en los libros, en internet o en cualquier otra fuente de información.

Una segunda dimensión del paso de la visión simple a la visión compleja es la de la concepción dialógica-dialéctica del conocimiento. ${ }^{12}$ En la visión simplificadora no cabe la idea de que dentro del proceso de conocimiento pueda existir error o ilusión, que el conocimiento pueda ser ciego a determinadas condiciones o elementos de la realidad. La visión de complejidad concibe el error y la ilusión como elementos permanentemente presentes en todo proceso cognitivo, y la ceguera ante determinados elementos de la realidad, como un aspecto inevitable dentro del camino para conocer.

Resulta tan evidente y natural la presencia del error en el conocimiento que Morin ${ }^{13}$ llega a hacer una primera definición tentativa de la verdad como el anti-error, es decir, como el proceso mediante el cual se desvela el error dentro de un problema o proceso. Resulta tan natural la presencia posible de cegueras en el conocimiento que también nos alerta a estar siempre en proceso de vigilancia de estas cegueras e ilusiones y sobre todo, a las que se producen cuando existe, en alguna persona o grupo, la actitud de "que posee la verdad".

Lonergan ${ }^{14}$ nos plantea la presencia de "sesgos" o desviaciones ${ }^{15}$ en la conciencia y nos describe la manera en que estos sesgos cierran la posibilidad de conocer, al excluir datos, preguntas, ciertos actos de intelección, cuestionamientos críticos sobre algunas realidades a las que el sujeto individual o el grupo son verdaderamente ciegos.

${ }^{12}$ Usamos aquí el término "dialógica-dialéctica" para utilizar la forma convergente-aunque no idéntica- en que Morin - dialógica- y Lonergan -dialéctica- adjetivan los procesos naturales y humanos en los que existen fuerzas opuestas que actúan simultáneamente en un fenómeno y que se influyen mutuamente.

${ }^{13}$ Op. cit.

${ }^{14}$ Op. cit.

${ }^{15}$ Designados con el término Bias, en inglés; cfr. caps. 6 y 7 de Insight. 
La presencia de un sesgo dramático de carácter psicológico puede hacer que sobre-opere el censor inconsciente y lleve al sujeto a no experimentar, indagar, entender, reflexionar, juzgar cierto aspecto de la realidad en la que vive. El sesgo individual del egoísmo puede hacer que el sujeto individual excluya preguntas o intelecciones que impliquen tener que renunciar a ciertos intereses individuales o a la comodidad con que se vive. También que los grupos sociales van desarrollando un sesgo grupal, que es parecido al sesgo dramático pero que actúa a nivel colectivo, cerrando al grupo completo a la experiencia, comprensión y juicio sobre ciertos elementos de la realidad que no son considerados relevantes o que cuestionan sus excesivos privilegios. Finalmente, la humanidad entera puede estar sujeta a un sesgo general del sentido común, que la lleve a poner la inteligencia práctica como única manera de conocer la realidad y que ciegue a los seres humanos respecto a todo conocimiento que no sea inmediato y útil, conduciendo al largo ciclo de decadencia de las civilizaciones.

La visión dialógica-dialéctica del conocimiento tiene que incorporar explícitamente la conciencia de que existen estos posibles sesgos en el modo en que construimos conocimiento los seres humanos.

Por otra parte, la visión tradicional del conocimiento también excluye tanto el mito como las creencias. El mito es considerado precisamente como lo opuesto al conocimiento, como el anti-conocimiento y la superstición, y no como una forma distinta de conocimiento que no solamente fue la forma dominante en las civilizaciones ancestrales, sino que existe y sigue estando presente en muchas formas de conocimiento contemporáneo. La creencia, por otra parte, es recluida en el ámbito de lo religioso y no se acepta tampoco que pueda haber creencia en el proceso de conocimiento. Sin embargo, desde la perspectiva de Lonergan, ${ }^{16}$ muy poco del conocimiento es autogenerado por los sujetos y la mayor parte se sustenta en conocimientos previos, generados por otro, que se asumen como verdaderos. Si aceptamos que una creencia es una afirmación que se considera verdadera sin ser verificada y sin cuestionarse, entonces vemos que el avance del conocimiento humano se sustenta en buena medida en la creencia.

${ }^{16}$ Método..., op. cit. 
En el campo educativo, esta visión dialógica-dialéctica introducirá sin duda cambios sustanciales en los procesos de aprendizaje que, tradicionalmente, se centran en la autoridad del conocimiento que es infalible, carente de posibilidades de error o cegueras o desviaciones, y por extensión, en la autoridad del docente, que es el depositario de este conocimiento cuasi-sobrehumano. La introducción de la visión del conocimiento como un proceso sujeto a autocorrección y siempre en peligro de caer en el error o en la ilusión ${ }^{17}$ de generar percepciones falsas si se le mitifica o se le pone en posición de divinidad intocable, pero siempre en posibilidad de nuevas preguntas y nuevos descubrimientos cuando se le coloca en su justa dimensión humana, reintroduciría la dimensión humana en la educación y haría del proceso de conocimiento una aventura apasionante y significativa para los educandos.

Dentro de la visión dialógica-dialéctica se encuentra también el riesgo permanente de caer en la dinámica del error o la ilusión, de dejarse llevar por los sesgos de la conciencia y caer en la dinámica que destruye el conocimiento auténtico y que se manifiesta en formas cosificantes del mismo, tales como la racionalización, el conceptualismo, la normalización del conocimiento de acuerdo a los parámetros convencionales o el relativismo que niega toda posibilidad de afirmación de verdad. Pero esta visión de los riesgos ayudará sin duda a los educadores y a los educandos a mantener una vigilancia crítica y autocrítica en los procesos de enseñanza-aprendizaje, para evitar caer en estos errores que reproducen y refuerzan la visión simplificadora del conocimiento, como parece suceder con demasiada frecuencia en las instituciones educativas.

En tercer lugar, el paso hacia la visión de complejidad incluye la reintroducción del sujeto cognoscente en su proceso de conocimiento que generará una nueva visión de la objetividad. Esta tercera dimensión resulta fundamental para humanizar el conocimiento y revertir el proceso de enajenación al que ha estado sometido el ser humano, como productor de conocimiento a partir de la falsa noción de objetividad, como exclusión deliberada de la subjetividad y, por lo tanto, del sujeto que conoce.

${ }^{17}$ E. Morin, Los siete saberes necesarios para la educación del futuro, 2001, Buenos Aires, ed. Nueva visión. 
"La ocultación de la subjetividad es el colmo de la subjetividad", dice Morin ${ }^{18} \mathrm{y}$ agrega que la construcción de conocimiento objetivo no comporta la anulación de la subjetividad, sino por el contrario, su pleno empleo, el ejercicio de la pasión por lo verdadero.

De la misma manera, Lonergan afirma que "la objetividad es el resultado del ejercicio auténtico de la subjetividad", ${ }^{19}$ es decir, de la vivencia atenta de las experiencias, la construcción inteligente de ideas y conceptos a partir de preguntas e imágenes y la afirmación razonable de juicios sustentados en pruebas y evidencias suficientes, debidamente articuladas.

Por lo tanto, una nueva visión del conocimiento conducirá a esta nueva perspectiva sobre la objetividad, como producto del ejercicio auténtico de la subjetividad, lo que llevará a la reintroducción del sujeto que conoce en su propio conocimiento y, por lo tanto, a la progresiva humanización del conocimiento.

Finalmente, una cuarta dimensión tiene que ver con lo que aquí llamamos polimorfismo del conocimiento, es decir, con la multiplicidad de formas en las que el conocimiento se desarrolla y se manifiesta en la vida humana. Tradicionalmente se acepta como conocimiento solamente el conocimiento científico y se desecha o desprecia cualquier otro tipo. Sin embargo, el conocimiento se manifiesta, por el polimorfismo de la conciencia, en muy distintas formas. Tocaremos ahora las tres formas generales más importantes de conocimiento que Lonergan denomina campos de la significación ${ }^{20}$ y que son: el campo del sentido común, el campo de la teoría y el campo de la interioridad.

El campo del sentido común es el ámbito del conocimiento altamente especializado que tiene que ver con la resolución de problemas de la vida cotidiana (saber tradicional); se caracteriza por su interés en lo particular concreto, su carácter práctico e inmediato y su modo de proceder relacionando los objetos con la experiencia del sujeto. El campo de la teoría, en cambio, es el de conocimiento que tiene que ver con las ciencias y se caracteriza por su interés en lo universal concreto, su

${ }^{18}$ E. Morin, El Método II. La vida de la Vida, 1997, Madrid, Ediciones Cátedra, p. 347.

${ }^{19}$ B. Lonergan, Método en Teología, op. cit., p. 258.

${ }^{20}$ Ibid., cap. 3. 
pretensión de generalización, su carácter no práctico y su visión de largo plazo, así como por su modo de proceder, en el que se relacionan los objetos entre sí y no con la percepción del sujeto. Finalmente, el campo de la interioridad se caracteriza por relacionar al sujeto consigo mismo, explorando y conociendo las operaciones que conforman la estructura misma del conocimiento y no los objetos; su mirada es también de largo alcance y su carácter no es práctico en el sentido utilitario.

En general, la visión imperante magnifica el papel del conocimiento teórico en la educación -aunque, como decíamos, tiende a deformar el sentido de lo teórico-, a mirar despectivamente el conocimiento del sentido común - por considerarlo no ilustrado-y a ignorar prácticamente el campo de la interioridad o a considerarlo un aspecto relacionado con lo mítico, lo esotérico o lo religioso - por no comprenderlo adecuadamente-; sin embargo, habría que introducir en el campo educativo una reflexión sobre estos campos de significación y su posible introducción para un enriquecimiento del proceso de aprendizaje.

El campo del sentido común es el tipo de conocimiento en el que el educando vive su vida cotidianamente -al igual que los educadoresy del que tiene mayor número de experiencias significativas, preguntas, ejemplos y juicios, que indican modos concretos de entender, explicar y resolver los problemas de la existencia práctica, debajo de los cuales existen principios o problemas científicos, antropológicos, sociológicos o hasta filosóficos. ¿Por qué no tomar entonces el conocimiento del sentido común, que es el conocido-conocido de los educandos, como punto de partida para construir desde allí el conocimiento marcado en el currículo?

Iniciar el proceso de conocimiento a partir de ejemplos del sentido común y del rescate de lo que el educando ya sabe acerca de ellos puede ser un buen generador de motivación para el aprendizaje, que aporte algunos datos - que posteriormente habrá que discernir críticamente- $\mathrm{y}$ genere un buen número de preguntas para emprender la búsqueda. A partir de estos ejemplos iniciales, se pueden ir tejiendo los conocimientos teóricos, construyendo comprensión de los fenómenos, apoyando el proceso de conceptualización y formulación de las ideas; incentivando la 
emergencia de preguntas críticas y la reflexión que apoye en el camino hacia el juicio; de hecho, que concluya el proceso de conocimiento.

El conocimiento teórico auténtico es el que trata de construir explicación de los fenómenos - es decir, relaciones inteligibles entre los objetos o componentes- a partir de preguntas adecuadas, imágenes pertinentes de apoyo, intelecciones que generen ideas, conceptualización que pueda formularse en lenguajes especializados. Sin embargo, este proceso es uno que incluye, como habíamos dicho, emoción, pasión, pulsión, posibilidad de acierto y de error o ilusión, afirmación de verdades que nos abran a la realidad o repetición de juicios previos que pueden cerrarnos a la comprensión de los fenómenos y acabar por poseernos. En este proceso, existe el sentimiento de verdad, que nos hace comprometernos con nuestras afirmaciones cuando llegamos a ellas y defenderlas con argumentos, pero también con pasión sustentada por argumentos apasionados. Todo esto tiene que ser contemplado en el proceso de conocimiento teórico que se busca comunicar y generar en las aulas para que sea realmente un proceso de conocimiento.

El campo de la interioridad nos hace pensar no solamente en objetos, sino sobre nuestro propio pensar, pensar sobre nuestros procesos de pensamiento. De este modo, no se trata de un campo esotérico o religioso sino de un campo indispensable para que la educación forme educandos no solamente capaces porque poseen muchos conocimientos sólidamente construidos y pueden aplicarlos a situaciones concretas, sino que conocen y han ido apropiando su propio proceso de conocimiento, de manera que son suficientemente concientes de su ser sujetos que conocen, como para poder seguir durante toda su vida profesional y personal generando y regenerando sus propios conocimientos, sin la necesidad de depender de un docente o de una institución educativa.

De manera que la introducción y adecuada combinación del conocimiento del sentido común, el conocimiento teórico y el conocimiento de interioridad, será una estrategia importante para revitalizar y volver a hacer significativo el proceso de aprendizaje, y para generar personas capaces de generar conocimiento y no solamente poseedores de conceptos. 
Como en el caso de la visión de ser humano, que es generada/generadora de educación, el paso fundamental que se tiene que dar es el que va desde una visión abstracta hacia una visión concreta; en este caso, del proceso de conocimiento. Esto implica un viraje epistemológico desde posturas conceptualistas y racionalistas hacia una postura realista crítica -en el sentido lonerganiano del término- o hacia una postura realista relacional relativa y múltiple como la llama Morin, visiones que sin ser exactamente equivalentes, son profundamente convergentes y pueden ser, ambas, muy orientadoras para el proceso educativo.

Este paso fundamental, este viraje epistemológico no puede darse sin una profunda y seria conversión intelectual, es decir, sin un proceso en el que cada sujeto educador deje atrás el supuesto que lo hace pensar que el proceso de conocimiento es algo bien conocido y algo que domina a la perfección, por ser su campo de trabajo cotidiano, y lo haga introducirse en un proceso en el cual experimente en carne propia la estructura dinámica y compleja del conocimiento humano y verifique cómo opera el conocimiento a partir del modo en que opera él o ella misma como sujeto, conociendo.

Esto significa hacer un ejercicio introspectivo que permita descubrir el modo en que experimenta y adquiere datos de la realidad o de su propia conciencia, la manera en que genera ideas a partir de la comprensión de la inteligibilidad de esos datos y de la exploración inteligente de posibilidades, del modo en que reflexiona críticamente y llega a la intelección reflexiva que lo hace afirmar un juicio, un "incondicionado virtual", conociendo las condiciones de esta afirmación y el modo en que se cumplen estas condiciones y sabiendo los límites y alcances de esta afirmación verdadera, cierta o probable.

Una vez hecho este ejercicio, cuando el educador haya caído en la cuenta de su propio proceso y sea capaz de autoafirmarse con el juicio básico: yo soy un sujeto cognoscente, argumentando y sustentando esta afirmación, será posible que este educador inicie la reorientación de su visión del conocimiento y pueda facilitar procesos de conocimiento en sus educandos. Pero llegar a esta primera autoafirmación no es el punto final de la conversión intelectual, sino solamente el gran punto de partida, el enorme paso necesario para iniciar el camino con 
un rumbo nuevo. Es lo que hace que el reto sea tan difícil de afrontar, pero precisamente es también lo que lo hace un proyecto profundamente creativo y apasionante, por el que vale la pena apostar, invirtiendo el esfuerzo y la constante auto-vigilancia crítica que son necesarios en la vida de todo educador, para evitar caer en el riesgo siempre presente, siempre oculto, siempre confortable, de la rutina y la repetición. Solamente así podrán acortarse las distancias entre las múltiples dimensiones del conocimiento en la Educación, que se encuentran hoy desarticuladas.

\section{La dialógica: transmisión-descubrimiento-construcción del conocimiento en el aula}

Una consecuencia fundamental del paso desde la visión simple hacia la visión compleja del conocimiento tiene que ver con el falso dilema entre transmisión y construcción del conocimiento en el aula, que se ha debatido durante mucho tiempo entre los estudiosos de la educación. La visión simplificadora tradicional ha sostenido que el proceso educativo consiste en la transmisión de conocimientos del educador al alumno -visión centrada en la enseñanza-, proceso en el que el educando es un simple espectador u objeto pasivo, un mero receptor de lo que el profesor le enseña.

Esta visión simplificadora tradicional ha sido sustituida en tiempos recientes por la perspectiva que centra el proceso educativo en el aprendizaje y que postula que el proceso en el aula consiste en la construcción del conocimiento por parte del educando, que se convierte en un sujeto activo del proceso de su propio aprendizaje. Sin embargo, esta visión parece ser una nueva visión simplificadora que podría llamarse visión simplificadora moderna o visión simplificadora constructivista.

Si en la primera visión se deja al estudiante como un mero receptor pasivo del conocimiento que le llega desde el profesor, en la segunda se deja al docente como un mero promotor de experiencias que pongan al estudiante en situación de construir su propio aprendizaje, pero se 
le niega toda posibilidad de comunicar o transmitir su propio saber al estudiante. En la primera perspectiva, se borra el término aprendizaje por subrayar la enseñanza, mientras en la segunda se proscribe el término enseñanza por enfatizar el aprendizaje. Si bien en el caso de la visión moderna o constructivista se trata de un asunto de énfasis, es cierto que muchas veces, en la práctica, se cae en el extremo de negar toda posibilidad de transmisión o de enseñanza e incluso se convierte en algo incorrecto usar el término enseñanza o enseñar.

Si retomamos la perspectiva lonerganiana del conocimiento de dos vías -la vía ascendente y la vía descendente-, podemos ver que existe una alternativa compleja que nos permite visualizar de una manera más integral el proceso educativo, convirtiéndolo en un proceso de enseñanza-aprendizaje y no solamente en un proceso de aprendizaje o en un proceso de enseñanza.

El proceso de construcción de conocimiento se da en el marco de una interacción constante y dialógica entre la transmisión y el descubrimiento, es decir, entre la enseñanza y el aprendizaje. Juntos, el docente y el estudiante construyen el conocimiento, siempre en esta interacción en la cual existe una vía ascendente mediante la cual se van recopilando datos y experiencias que se relacionan, se procesan inteligentemente, se reflexionan críticamente y llevan a juicios de hecho; y existe también una vía descendente, en la cual existen juicios verdaderos que vienen de la tradición o de la herencia del conocimiento ya construido que se van transmitiendo vía el docente a los estudiantes, proponiendo su comprensión, tratando de que éstos enriquezcan la experiencia del estudiante que reiniciará con este enriquecimiento nuevos procesos de descubrimiento.

El educando es, entonces, un actor esencial, el sujeto protagonista del proceso de su propio aprendizaje, que va construyendo su propio conocimiento a partir de procesos de descubrimiento y de recepción activa de los conocimientos del profesor. El docente es también un actor fundamental, el sujeto que facilita las experiencias de aprendizaje adecuadas para que los estudiantes construyan su aprendizaje por descubrimiento, pero que también transmite sus propios conocimientos, de 
manera que los alumnos puedan construir conocimiento también a partir de esta transmisión o enseñanza. En este proceso, también ocurre que los docentes aprenden y entran en la vía de descubrimiento a partir del enriquecimiento que les brinda el contacto profundo y vital, desde el irrestricto deseo de conocer ${ }^{21}$ que es compartido con sus educandos; y ocurre de igual modo que el estudiante puede transmitir y llegar a enseñar elementos de la herencia, conocimientos o ideas preconstruidas y aceptadas en la cultura en la que vive a sus propios compañeros e incluso al docente.

Este es el producto revitalizante de una búsqueda genuina de conocimiento a partir del cambio radical en la visión del conocer, que genera el proceso educativo y es, a su vez, generada por el proceso educativo; un producto que sin duda contribuirá a que el sistema educativo se aproxime progresivamente a la reforma que requiere urgentemente, para responder a los desafíos complejos del mundo global del siglo XXI.

${ }^{21}$ B. Lonergan, Insight, op. cit. 